\title{
LA-UR-20-29905
}

Approved for public release; distribution is unlimited.

Title: $\quad$ Summer 2020 Student Survey Highlights

Author(s): $\quad$ Robbins, Scott Allen

Intended for: On-going meetings with Brightspot, the consultancy who is tasked with the Study Center remodel project. Presentation to be used to have a better understanding of the student populations needs as they pertain to the Study Center.

Issued: 
Disclaimer:

Los Alamos National Laboratory, an affirmative action/equal opportunity employer, is operated by Triad National Security, LLC for the National Nuclear Security Administration of U.S. Department of Energy under contract 89233218CNA000001. By approving this article, the publisher recognizes that the U.S. Government retains nonexclusive, royalty-free license to publish or reproduce the published form of this contribution, or to allow others to do so, for U.S. Government purposes. Los Alamos National Laboratory requests that the publisher identify this article as work performed under the auspices of the U.S. Department of Energy. Los Alamos National Laboratory strongly supports academic freedom and a researcher's right to publish; as an institution, however, the Laboratory does not endorse the viewpoint of a publication or guarantee its technical correctness. 


\section{Summer 2020 Student Survey Highlights}

LANL Student Programs Office

Scott Robbins

September 2020

NATIONAL LABORATORY 


\section{Data Collection}

As we ramped up our Summer 2020 internship season we expected to be able to learn a lot about running a virtual internship program. Formal data collection occurred at four different points.

- All new hire students were asked about their onboarding experience during the 3rd week after starting - 130 responses

- 258 students completed the 2020 Student Survey

- 43 participants, mostly students, completed the questionnaire aimed at revealing lessons learned from our Summer 2020 Student Symposium 


\section{What Summer 2020 New Hires Had to Say}

\section{How did they hear about opportunities at LANL?}

- LANL staff visits to universities

- Friends and families

- Special programs like SULI, Critical Technologies Studies Program, Mickey Leland Energy Fellowship

- Faculty members and others at their universities

- Other LANL students

- LANL visits to conferences and job fairs

- Internet searches and LANL web pages

- Peers with LANL internship experiences 


\section{Comparing Summer 2020 Onboarding with 2019}

Time required to have tools for the job (computers, network access, etc.)

\begin{tabular}{|l|l|l|l|l|}
\hline & 2 days & 1 week & 2 weeks & $>2$ weeks \\
\hline 2019 & $55 \%$ & $32.7 \%$ & $9.4 \%$ & $3.0 \%$ \\
\hline 2020 & $31.5 \%$ & $32.3 \%$ & $27.7 \%$ & $8.5 \%$ \\
\hline
\end{tabular}

Time required to have conversation regarding expectations with mentor

\begin{tabular}{|l|l|l|l|l|}
\hline & 2 days & 1 week & 2 weeks & $>2$ weeks \\
\hline 2019 & $62.6 \%$ & $23.4 \%$ & $7.0 \%$ & $7.1 \%$ \\
\hline 2020 & $66.2 \%$ & $22.3 \%$ & $6.2 \%$ & $5.4 \%$ \\
\hline
\end{tabular}




\section{Mentor Communication Frequency in 2020}

How frequently did your mentor communicate with you? 258 responses

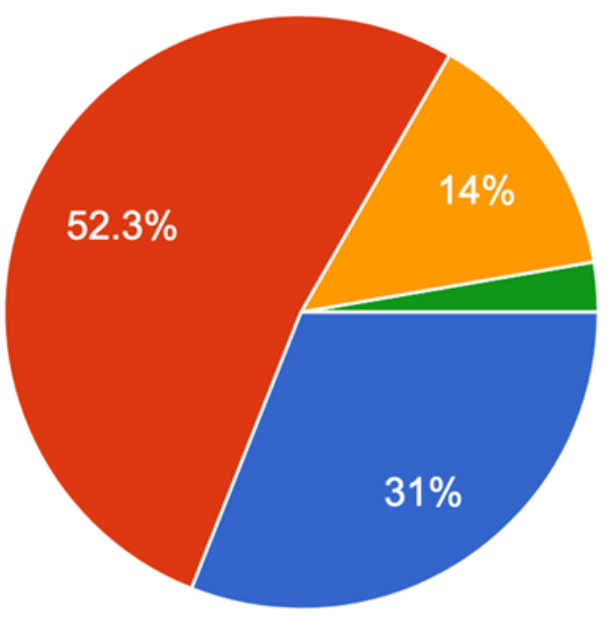

Daily

Two or three times per week

Once per week

Once or twice per month 


\section{Mentor Communication Modality in 2020}

By what means did you and your mentor most frequently interact? 258 responses

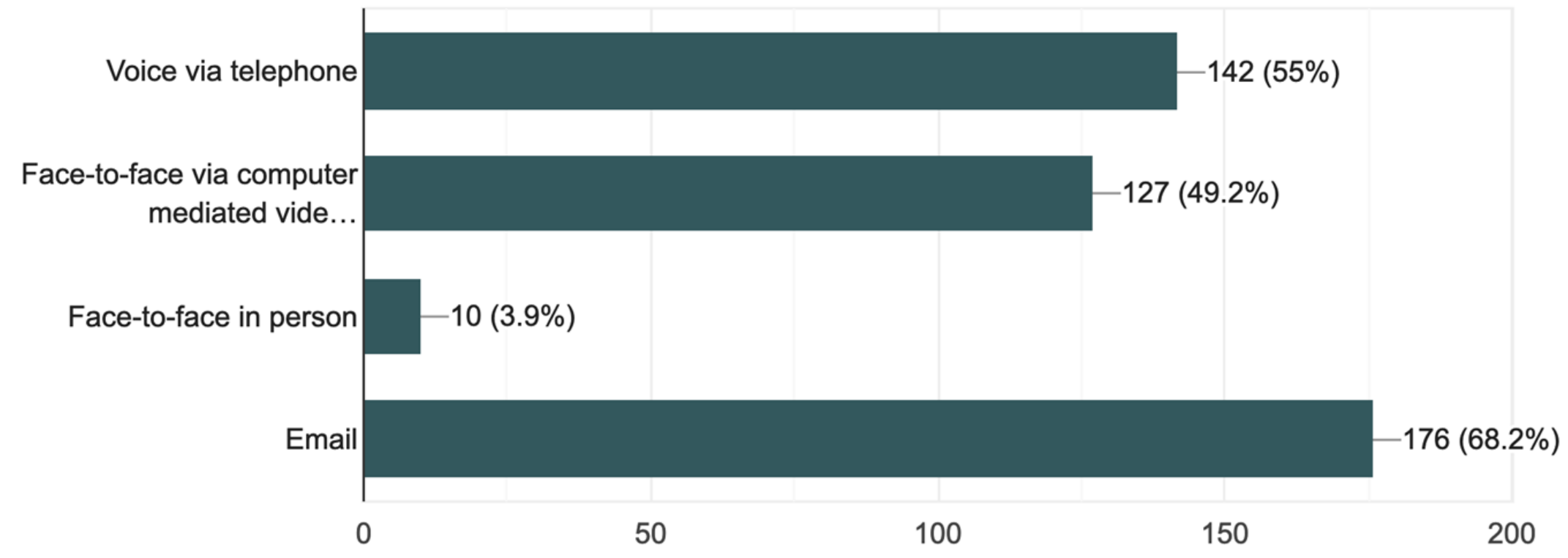




\section{9 vs. 2020 Mentor Support and Social Inclusion}

To what extent did you feel that your mentor was involved and supported you in your internship experience?

- No significant difference between 2019 and 2020

To what degree did you feel included in your workgroup?

- Slightly higher reported sense of inclusion in 2019 (56.8\% vs. 51.4\%) 


\section{Recommendations to Peers?}

If you worked remotely, would you recommend a virtual internship at the Lab to your peers? 258 responses

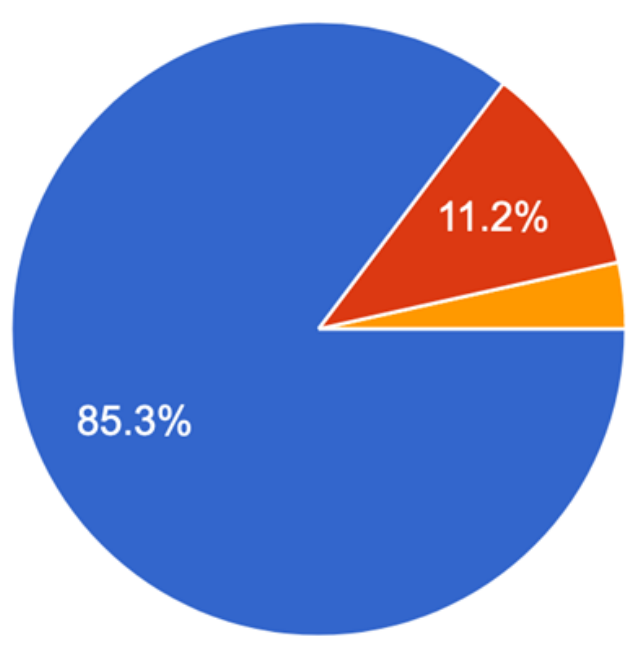

Yes

No

Not applicable, I worked onsite

Note: "Yes" about the same as 2019 but "No" was higher this year (11.2\% vs. $1.8 \%)$. 


\section{Overall Rating of the Summer 2020 Experience}

How would you rate your internship overall?

258 responses

150

$128(49.6 \%)$

100

$101(39.1 \%)$

50

$\begin{array}{ccc}0 & 2(0.8 \%) & 25(9.7 \%) \\ 1 & 2 & 3 \\ & \\ \text { Note: No significant difference between } 2019 \text { and } 2020 .\end{array}$ 


\section{Two Best Things About the Experience?}

- I got exposed to the lab even through the seminars and "Designing your Career" talks. I also got exposed to different applications of my field which was interesting.

- Good integration with the group. Excellent autonomy to collaborate in small groups and get work done with minimal regular interruptions.

- Support from mentors and leadership, ability to work on multiple things

- Intellectual work environment and strong mentor support

- I love how my mentor encourages reading and learning about the field we work in. I also am very excited about the paper that we are starting to write.

- 1. My mentor was fantastic 2. The project I was a part of was fun and I learned a lot

- Solving an interesting, complicated, and challenging problem in terms of the actual scientific work I did. Having control over when I start working every day and being able to focus on work due to being virtual. 


\section{Two Most Challenging Things About the Experience?}

- Remote technology was a difficult obstacle. I don't have a LANL laptop, so I cannot VPN in, which made things even more challenging.

- 1. When working with other interns some might have more experience and not let you take the wheel at times. 2. Not being able to experience LANL in person

- Limitations of working from home. Both technologically and socially.

- Like I mentioned, navigating the spoken and unspoken expectations of my mentors. The other least positive was that zoom meetings are kind of tiring, and most days I was on zoom for around 4 hours.

- There was only one suboptimal aspect: Needing to use a terminal session through portal.lanl.gov to do some work on a LANL Windows computer for security reasons, instead of my Mac laptop, was clunky and slow.

- Not being able to be on campus, and not being able to be on campus 


\section{Sharing Results}

Did or will you have an opportunity to share the results and accomplishments of your internship? 256 responses

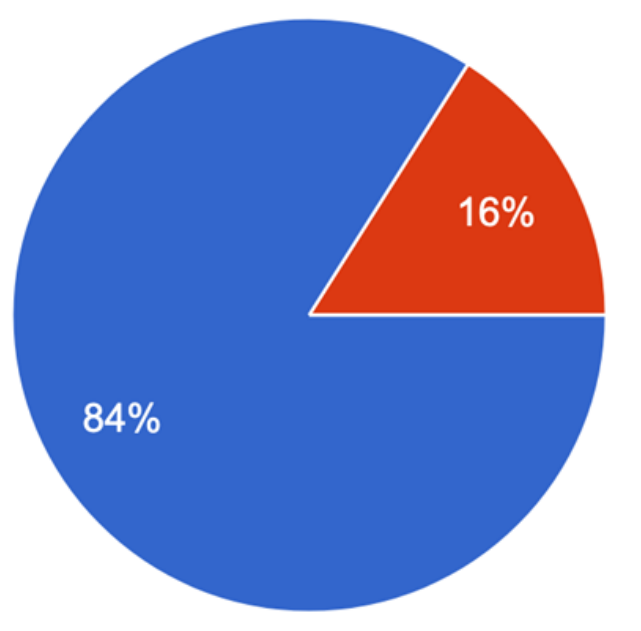

Yes

No

Note: "Yes" responses were slightly higher in 2020 than in 2019 (84\% vs. 81.4\%) 